EXERO, e-ISSN 2655-1519, p-ISSN 2655-1527, Vol. 02, No. 01, Mei 2019 EXERO Journal of Research in Business and Economics http://e-journal.usd.ac.id/index.php/exero

Fakultas Ekonomi, Universitas Sanata Dharma Yogyakarta

\title{
PENGARUH PERSEPSI KONSUMEN PADA STORE ATMOSPHERE TERHADAP IMPULSE BUYING MELALUI SHOPPING EMOTION PLEASURE
}

(Studi pada Konsumen Mirota Kampus Babarsari Yogyakarta)

\author{
Dinda Prasetya Aurellia \\ CANNIS App. Bandung \\ dindaprasetyaaurellia@gmail.com
}

DOI:doi.org/10.24071/exero.2019.02.01.04

\begin{abstract}
This study aimed to investigated the influence of consumers' perceptions on store atmosphere toward impulse buying and shopping emotion pleasure. This study also investigated the mediating role of shopping emotion pleasure. By using accidental sampling technique, this study took 100 consumers of Mirota Babarsari Yogyakarta who were at least 17 years old. The data were obtained by using a structured questionnaires and analyzed by using Path Analysis via Regression. The results indicated that consumers' perceptions on store atmosphere affected impulse buying, consumers perceptions on store atmosphere affected shopping emotion pleasure and shopping emotion pleasure fully mediated the relation between consumers' perceptions on store atmosphere and impulse buying.
\end{abstract}

Keywords: store atmosphere, shopping emotion pleasure, impulse buying

\section{PENDAHULUAN}

Perkembangan zaman membuat persaingan antar-perusahaan semakin ketat, tak terkecuali persaingan antar-perusahaan ritel seperti misalnya toko swalayan. Ketatnya persaingan mendorong toko swalayan untuk melakukan segala daya upaya melalui berbagai inovasi dan strategi yang dimaksudkan tidak hanya agar konsumen terdorong untuk datang dan berbelanja. Upaya-upaya yang dilakukan tidak hanya sebatas menawarkan produk-produk yang beraneka ragam atau produk-produk berkualitas dengan harga menawan, namun juga menciptakan suasana toko (store atmosphere) untuk menimbulkan emosi positif pada konsumen saat berada dalam toko (shopping emotion pleasure). Harapannya, perasaan emosi positif yang 
menyenangkan saat berada dalam toko akan memunculkan perilaku berbelanja tertentu yang salah satunya adalah pembelian tak terencana (impulse buying)

Perasaan senang yang timbul pada diri konsumen dapat terjadi apabila suasana di dalam toko tersebut menyenangkan. Mowen dan Minor (2002:139) mengatakan bahwa suasana toko (store atmosphere) berhubungan dengan bagaimana pihak perusahaan dapat memanipulasi desain bangunan, ruang interior, tata ruang, lorong-lorong, tekstur karpet dan dinding, bau, warna, bentuk, dan suara yang dialami oleh konsumen. Selain itu, suasana toko juga dapat memengaruhi keadaan emosional pembeli. Ketika suasana konsumen bergairah secara positif, maka pembeli cenderung menghabiskan lebih banyak waktu di toko tersebut.

Store atmosphere yang telah dirancang sedemikian rupa diharapkan dapat meningkatkan emosi konsumen secara positif, agar konsumen merasa nyaman dan betah saat melakukan aktivitas belanja, dan diharapkan akan melakukan pembelian. Emosi yang timbul pada saat melakukan aktivitas belanja ini disebut dengan shopping emotion. Menurut Daniel Goleman (1996:97), emosi merujuk pada suatu perasaan dan pikiran yang khas, suatu keadaan biologis dan psikologis dan serangkaian kecenderungan untuk bertindak. Hawkins (2010: 241) mengemukakan bahwa emosi dapat diidentifikasikan sebagai perasaan suka atau tidak suka terhadap sesuatu yang lebih spesifik. Emosi adalah perasaan terhadap situasi tertentu, produk, iklan dan sebagainya. Berdasarkan pendapat tersebut, dapat dikatakan bahwa shopping emotion adalah perasaan suka atau tidak suka seseorang terhadap suasana toko yang diciptakan. Perasaan suka seseorang terhadap suasana toko disebut dengan shopping emotion pleasure yang dapat memicu konsumen melakukan pembelian.

Usaha manajer toko, swalayan Mirota Kampus Babarsari Yogyakarta khususnya, dalam menciptakan store atmosphere agar dipersepsikan baik oleh konsumen, bukan tanpa alasan. Mereka meyakini bahwa persepsi konsumen pada store atmosphere dapat mendorong pembelian yang lebih banyak sehubungan dengan kecenderungan pembelian tidak terencana (impulse buying) melalui emosi positif dalam bentuk shopping emotion pleasure seperti perasaan betah dan ingin berlama-lama di dalam toko. Namun persoalannya adalah apakah memang persepsi konsumen pada store atmosphere berpengaruh terhadap impulse buying, apakah persepsi konsumen pada store atmosphere berpengaruh positif terhadap shopping 
emotion pleasure, dan apakah shopping emotion pleasure berpengaruh positif terhadap impulse buying. Melalui jawaban atas tiga persoalan tersebut, maka dapat diketahui pengaruh persepsi konsumen pada store atmosphere terhadap impulse buying melalui shopping emotion pleasure .

\section{KAJIAN PUSTAKA}

\section{Shopping Emotion}

Menurut Hawkins, Mothersbaugh, dan Best (2004) emosi merupakan suatu perasaan yang tidak dapat dikontrol namun dapat memengaruhi perilaku atau kebiasaan seseorang. Suasana hati atau emosi seseorang atau kondisi psikologi seseorang saat pembelian dapat memiliki dampak besar pada apa yang dia beli atau bagaimana dia menilai pembeliannya (Solomon, 2007). Berdasarkan definisi di atas, Shopping Emotion merupakan emosi atau perasaan yang tidak bisa dikontrol namun memiliki pengaruh besar pada pembelian.

Menurut Mehrabian dan Russell (dalam Samuel, 2005) shopping emotion dapat diuraikan menjadi tiga tipe, yaitu: Pleasure, Arousal, dan Dominance. Pleasure mengacu pada tingkat dimana individu merasakan baik, penuh kegembiraan, senang, bahagia, nyaman, dan betah yang berkaitan dengan situasi tertentu. Arousal mengacu pada tingkat dimana seseorang merasakan siaga, digairahkan, atau situasi aktif. Dominance ditandai dengan laporan konsumen yang merasa dikendalikan sebagai lawan mengendalikan, mempengaruhi sebagai lawan dipengaruhi, terkendali sebagai lawan diawasi, penting sebagai lawan dikagumi, dominan sebagai lawan bersikap tunduk, dan otonomi sebagai lawan dipandu.

\section{Store Atmosphere}

Store Atmosphere merupakan penciptaan suasana toko melalui visual, penataan ruang dalam toko (instore) termasuk desain bangunan, ruang interior, tata ruang, lorong, bau, warna, cahaya, musik dan ruang luar (outstore) yang dapat menciptkan lingkungan pembelian yang nyaman, sehingga dapat memengaruhi persepsi dan emosi konsumen untuk melakukan pembelian (Levy:2001:576), (Sutisna; 2001:164), (Mowen dan Minor 2002:139). Lebih jauh, Donovan dan Rositter (dalam Peter dan Olson, 2014 : 265) menyatakan bahwa Store Atmosphere 
melibatkan afeksi dalam bentuk keadaan emosi konsumen yang berbelanja di dalam toko yang mungkin tidak sepenuhnya disadari olehnya. Kotler dan Keller (2007:177) mengemukakan bahwa setiap toko harus mempunyai atmosfer terencana yang sesuai dengan pasar sasarannya dan memikat konsumen untuk membeli. Menurut Barry dan Evans (2004:455), "Atmosphere can be divided into these key elements: exterior, general interior, store layout, and displays." Elemen store atmosphere ini meliputi: bagian luar toko (exterior), bagian dalam toko (general interior), tata letak ruangan (store layout), dan pajangan (Interior Point of Interest Display).

Bagian luar toko memiliki pengaruh yang kuat kepada citra toko tersebut, sehingga harus direncanakan sebaik mungkin.Kombinasi dari exterior ini dapat membuat bagian luar toko menjadi terlihat unik, menarik, dan mengundang orang untuk masuk ke dalam toko. Elemen-elemen exterior terdiri dari beberapa subelemen: pertama, storefront (bagian depan toko) yang meliputi kombinasi papan nama, pintu masuk, dan konstruksi bangunan. Storefront harus mencerminkan keunikan, kemantapan, kekokohan, atau hal-hal lain yang sesuai dengan citra toko tersebut. Kedua, marquee (simbol). Marquee adalah suatu tanda yang digunakan untuk memajang nama atau logo suatu toko. Marquee dapat dibuat dengan teknik pewarnaan, penulisan huruf, atau penggunaan lampu neon. Ketiga, entrace (pintu masuk). Pintu masuk harus direncanakan sebaik mungkin, sehingga dapat mengundang konsumen untuk masuk dan melihat ke dalam toko dan juga mengurangi kemacetan lalu lintas keluar masuk konsumen. Keempat, display window (tampilan jendela) yang dimaksudkan untuk mengidentifikasi suatu toko dengan memajang barang-barang yang mencerminkan keunikan toko tersebut sehingga menarik konsumen untuk masuk ke dalam toko. Kelima, uniqueness (keunikan) suatu toko bisa dihasilkan dari desain bangunan toko yang membuat beda dari toko yang lain. Keenam, height and size building (tinggi dan ukuran gedung). Tinggi dan ukuran gedung dapat memengaruhi kesan tertentu terhadap toko tersebut.Misalnya, tinggi langit-langit toko dapat membuat ruangan seolah-olah lebih luas. Ketujuh, sourrounding area (lingkungan sekitar), yakni keadaan lingkungan masyarakat dimana suatu toko berada, dapat memengaruhi citra toko tersebut.Jika toko lain yang berdekatan memiliki citra yang kurang baik, maka toko yang lain pun akan terpengaruh dengan citra tersebut. Kedelapan, parking (tempat parkir). Tempat 
parkir merupakan hal yang penting bagi konsumen. Jika tempat parkir luas, aman, dan mempunyai jarak yang dekat dengan toko, maka akan menciptakan atmosphere yang positif bagi toko tersebut.

General Interior atau yang disebuit bagian dalam toko. Bagian dalam toko harus dirancang untuk menarik perhatian pengunjung yang telah berada di dalam toko dan memudahkan mereka untuk mengamati, memeriksa, memilih, dan pada akhirnya melakukan suatu pembelian. Elemen-elemen general interior terdiri dari: pertama, flooring (lantai) . Penentuan jenis lantai, ukuran, desain dan warna lantai sangat penting, karena konsumen dapat mengembangkan persepsi mereka berdasarkan apa yang mereka lihat. Kedua, color and lightening (warna dan pencahayaan). Setiap toko harus mempunyai pencahayaan yang cukup untuk mengarahkan atau menarik perhatian konsumen ke daerah tertentu dari toko.Tata cahaya yang baik mempunyai kualitas dan warna yang dapat membuat suasana yang ditawarkan terlihat lebih menarik. Ketiga, scent and sound ( aroma dan musik) Jika layanan ini dilakukan, maka akan memberikan suasana yang lebih santai pada konsumen, khususnya konsumen yang ingin menikmati suasana yang santai dengan menghilangkan kejenuhan, kebosanan, maupun stress. Keempat, fixture (penempatan). Memilih peralatan penunjang dan cara penempatannya harus dilakukan dengan baik agar didapat hasil yang sesuai dengan keinginan. Kelima, temperature (suhu udara) . Perusahaan harus mengatur suhu udara, agar udara dalam ruangan agar jangan terlalu panas atau dingin. Keenam, dead area yang merupakan ruang di dalam toko dimana display yang normal tidak bisa diterapkan karena akan terasa janggal. Ketujuh, personel (pramuniaga) dalam artian pramuniaga yang sopan, ramah, berpenampilan menarik, cepat, dan tanggap akan menciptakan citra perusahaan di mata pengunjung. Kedelapan, cleanliness (kebersihan). Kebersihan dapat menjadi pertimbangan utama bagi konsumen untuk berbelanja di toko tersebut.

Pengelola toko harus mempunyai rencana dalam penentuan lokasi dan fasilitas toko (store layout/ tata letak). Pengelola toko juga harus memanfaatkan ruangan di dalam toko yang ada seefektif mungkin. Hal-hal yang perlu diperhatikan dalam merancang layout adalah sebagai berikut: pertama, allocation of floor space for selling, personnel, and customers. Dalam suatu toko, ruangan yang ada harus dialokasikan untuk Selling Space (Penjualan), Personnel Space (Ruangan Pegawai), 
dan Customers Space (Ruangan Pelanggan). Kedua, traffic flow (arus lalu lintas). Di dalam suatu toko, penentuan arus lalu lintas sangat penting untuk mempermudah konsumen dalam berbelanja. Ketiga, width of aisles (lebar gang) Jarak harus diatur sedemikian rupa agar konsumen merasa nyaman dan betah berada di toko.

Interior Point of Interest Display (Dekorasi Pemikat Dalam Toko). Interior point of interest display mempunyai dua tujuan, yaitu memberikan informasi kepada konsumen dan menambah store atmosphere. Interior point of interest display terdiri dari: pertama, theme setting display (dekorasi sesuai tema). Dalam suatu musim tertentu perusahaan dapat mendisain dekorasi toko atau meminta pramuniaga berpakaian sesuai tema tertentu. Kedua, ensemble display. Pengelompokan dan menampilkan barang dagangan di kategori terpisah. Ketiga, case display. Menampilkan display seperti pakaian dengan menggunakan mannequin. Yang terakhir, wall decoration (dekorasi ruangan). Dekorasi ruangan pada tembok bisa merupakan kombinasi dari gambar atau poster yang ditempel, warna tembok, dan sebagainya yang dapat meningkatkan suasana toko.

\section{Impulse Buying}

Solomon dan Rabolt (2014; 376) menyatakan bahwa impulse buying adalah suatu kondisi yang terjadi ketika individu mengalami perasaan terdesak secara tibatiba yang tidak dapat dilawan. Pendapat yang serupa juga disampaikan oleh Levy (2012:92) yang mendefinisikan impulse buying sebagai proses keputusan pembelian yang dilakukan secara spontan di suatu tempat ketika melihat produk tertentu. Menurut Rook dan Fisher (dalam Solomon 2014) kecenderungan untuk membeli secara spontan ini umumnya menghasilkan pembelian ketika konsumen percaya bahwa tindakan tersebut adalah hal yang wajar. Produk yang dibeli dari proses impulse buying umumnya tidak direncanakan sebelumnya atau tidak ada upaya untuk mencari produknya, seperti ketika membeli permen dan majalah atau permen karet secara spontan yang dipajang di dekat kasir pembayaran (e.g. Kotler dan Keller, 2016:391; Solomon dan Askegaard, 2007).

Menurut Mowen dan Minor (2002:10) impulse buying merupakan tindakan membeli yang sebelumnya tidak diakui secara sadar sebagai hasil dari suatu pertimbangan, atau niat membeli yang terbentuk sebelum memasuki toko. Menurut 
Hawkins (2010:107) impulse buying didefinisikan sebagai pembelian yang dibuat di dalam toko yang berbeda dari perencanaan konsumen untuk membuat prioritas saat memasuki toko. Dari beberapa pendapat, dapat disimpulkan bahwa impulse buying merupakan suatu pembelian yang tidak rasional, konsumen cenderung tidak melakukan perencanaan terlebih dahulu dan terjadi secara spontan karena munculnya suatu dorongan yang kuat untuk membeli dengan segera pada saat itu juga.

\section{Pengaruh Persepsi Konsumen pada Store Atmosphere terhadap Impulse Buying}

Menurut Schiffman (2015:30), perilaku konsumen merupakan studi tentang tindakan konsumen selama mencari, membeli, menggunakan, mengevaluasi, dan menghabiskan produk dan/atau layanan yang mereka harapkan akan memuaskan kebutuhan mereka. Selanjutnya, Kotler dan Keller (2009:166) berpendapat bahwa perilaku pembelian konsumen dipengaruhi oleh beberapa faktor budaya, sosial, pribadi, dan psikologi. Dalam memahami perilaku konsumen, terdapat beberapa faktor psikologis yang berpengaruh terhadap pembelian, di antaranya motivasi, persepsi, pembelajaran, dan memori.

Hawkins dan Mothersbough (2016:477) mengemukakan bahwa store atmosphere merupakan perpaduan dari seluruh fitur fisik pada lingkungan toko ritel yang memengaruhi penilaian konsumen terhadap citra toko, kualitas produk, suasana hati pembeli, kesediaan mereka untuk mengunjungi toko, dan bertahan. Toko dengan atmosfer yang baik dan atraktif dapat mempengaruhi konsumen untuk melakukan impulse buying. Hal yang mendorong perilaku pembelian impulsif pada konsumen adalah meliputi tampilan tata letak produk, pencahayaan, perilaku karyawan yang melayani, teknologi, lokasi toko, ketersediaan produk, dan variabel lainnya (Akram et al., 2016). Hipotesis pada penelitian ini adalah:

Hipotesis 1: Persepsi konsumen pada store atmosphere (X) berpengaruh terhadap impulse buying behavior (Y). 


\section{Pengaruh Persepsi Konsumen pada Store Atmosphere terhadap Shopping Emotion Pleasure}

Store atmosphere dipengaruhi oleh beberapa atribut seperti pencahayaan, tata letak, penyajian barang dagangan, perlengkapan, penutup lantai, warna, suara, bau, perilaku para tenaga penjualan dan kualitas pelayanannya. Suasana hati dan emosi positif yang ditimbulkan ketika seseorang berada di toko diperkirakan dapat meningkatkan kemungkinan terciptanya kepuasan pelanggan, yang dapat menghasilkan kunjungan berulang dan loyalitas terhadap suatu perusahaan (Hawkins dan Mothersbough, 2016:605). Pengelola usaha ritel dapat menciptakan emosi positif, kenikmatan estetika dan suasana hati yang bahagia bagi konsumen dengan mengendalikan faktor-faktor pendukung seperti pencahayaan, musik, cita rasa, dan dekorasi (Shen dan Tsuifang, 2011). Faktor sosial seperti hubungan yang interaktif antara penjual dengan konsumen, perilaku tenaga penjual yang ramah terutama ketika toko sedang ramai pengunjung juga merupakan bentuk stimulus keadaan toko yang berpengaruh terhadap terjadinya impulse buying (Mattila dan Wirtz, 2008).

Persepsi adalah proses ketika seseorang memilih, mengorganisir, dan menafsirkan stimulus yang diterimanya (Solomon, 2007:63). Menurut Sangadji dan Sopiah (2013:64) persepsi konsumen merupakan suatu proses yang timbul akibat adanya sensasi. Sensasi adalah aktivitas merasakan atau penyebab keadaan emosi. Berdasarkan penelitian sebelumnya, Anggoro (2013) membuktikan bahwa store atmosphere yang dirasakan oleh konsumen dapat memengaruhi emotional responses konsumen tersebut. Sangadji dan Sopiah (2013:66) mengungkapkan bahwa terdapat beberapa stimuli yang akan membuat suatu pesan lebih yang dirasakan konsumen. Salah satu stimuli yang memengaruhi persepsi konsumen yaitu faktor struktural, misalnya ukuran, bentuk, dan posisi. Hipotesis pada penelitian ini adalah:

Hipotesis 2: Persepsi konsumen pada store atmosphere (X) berpengaruh terhadap shopping emotion pleasure $(\mathrm{Z})$.

\section{Pengaruh Shopping Emotion Pleasure terhadap Impulse Buying}

Dalam melakukan pengambilan keputusan, seseorang akan berpikir secara rasional dan seksama untuk mempertimbangkan dampak positif dan negatif dari 
pilihannya. Namun pada keadaan lain, seseorang dapat sangat terpengaruh oleh emosinya ketika saat akan bereaksi terhadap suatu masalah (Solomon, 2017:335). Menurut Hawkins (2010:107) emosi merupakan suatu perasaan yang tidak dapat dikontrol namun dapat memengaruhi perilaku atau kebiasaan seseorang.

Suasana hati atau emosi seseorang atau kondisi psikologi seseorang saat pembelian dapat memiliki dampak besar pada apa yang dia beli atau bagaimana dia menilai pembeliannya (Solomon, 2007:65). Supriono (2017) membuktikan bahwa shopping emotion berpengaruh secara signifikan terhadap impulse buying. Respon emosional positif seperti rasa senang dan gairah memunculkan dorongan seseorang untuk terstimulasi, bersemangat, tidak terkendali, hingga melakukan pembelian secara impulsif (eg. Habib dan Qayyum, 2018; Lee dan Yi, 2008). Hipotesis pada penelitian ini adalah:

Hipotesis 3: Shopping emotion pleasure (Z) berpengaruh terhadap impulse buying (Y).

\section{Kerangka Konseptual Pengaruh Persepsi Konsumen pada Store Atmosphere terhadap Impulse buying melalui Shopping Emotion Pleasure}

Kerangka konseptual pada penelitian ini adalah sebagai berikut:

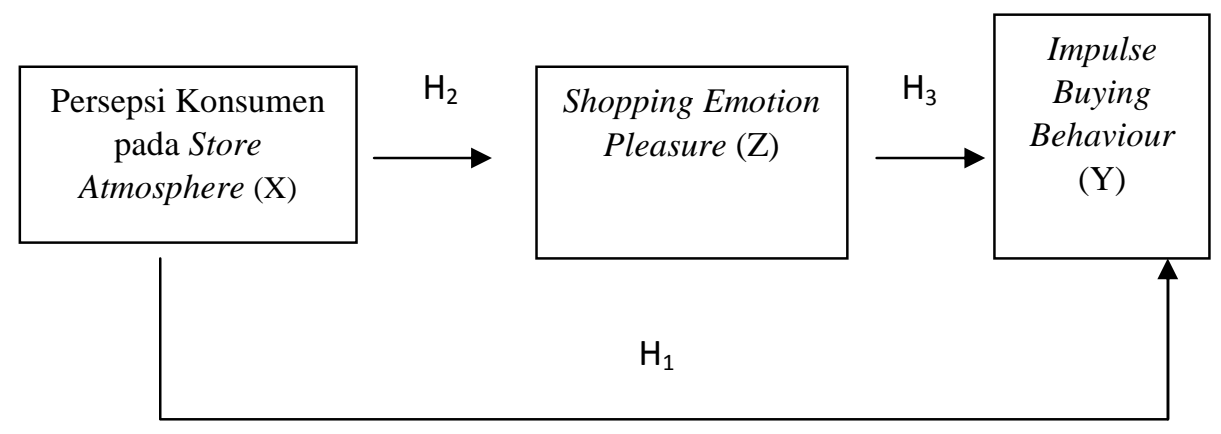

Gambar 1. Kerangka Konseptual

\section{METODE PENELITIAN}

Populasi target dari penelitian ini adalah semua konsumen Mirota Kampus Babarsari Yogyakarta yang berusia minimal 17 tahun. Jumlah sampel sebanyak 100 konsumen yang diambil dengan menggunakan teknik accidental sampling. 
Penelitian ini menggunakan tiga variabel yaitu persepsi konsumen pada store atmosphere sebagai variabel independen. Store atmosphere dilihat dari 5 dimensi yaitu exterior, interior, store layout dan interior point of interest display. Variabel shopping emotion pleasure dengan sebagai variabel Intervening, dan impulse buying sebagai variabel dependen. Skala yang digunakan untuk pengukuran menggunakan skala likert, dengan rentang 1-5. Data primer tentang karakteristik responden dan variabel dikumpulkan dengan menggunakan alat kuesioner yang telah diuji validitas dan reabilitas. Pengumpulan data dilaksanaan pada bulan Oktober sampai dengan November 2018 di lokasi seputar Mirota Kampus Babarsari Yogyakarta sesaat setelah konsumen selesai berbelanja.

Setelah data dikumpulkan dan diuji prasyarat statistik selanjutnya dianalisis dengan menggunakan alat analisis jalur (path analysis). Analisis jalur dilakukan jika terdapat suatu variabel intervening atau mediasi yaitu variabel yang bersifat perantara (jembatan) dari variabel independen ke variabel dependen. Pengujian prasyarat dan analisis jalur dilakukan dengan menggunakan alat bantu SPSS. Prosedur analisis jalur dilakukan dengan tahapan sebagai berikut:

1) Meregresi $Y=\rho_{\mathrm{mx}} \mathrm{X}+\varepsilon_{1}$ dan menguji hipotesis I bahwa persepsi konsumen pada store atmosphere $(\mathrm{X})$ berpengaruh terhadap impulse buying (Y).

\begin{tabular}{|c|c|}
\hline $\begin{array}{c}\text { Persepsi Konsumen } \\
\text { pada Store Atmosphere } \\
(\mathrm{X})\end{array}$ & $\begin{array}{c}\text { Impulse Buying } \\
\text { Behavior (Y) }\end{array}$ \\
\hline
\end{tabular}

Gambar 2. Persamaan Regresi X dan Y

2) Meregresi $Z=\rho_{\mathrm{mx}} \mathrm{X}+\varepsilon_{1}$ dan menguji hipotesis II bahwa persepsi konsumen pada store atmosphere $(\mathrm{X})$ berpengaruh terhadap shopping emotion pleasure $(\mathrm{Z})$.

\begin{tabular}{|c|c|}
\hline $\begin{array}{c}\text { Persepsi Konsumen pada } \\
\text { Store Atmosphere } \\
(\mathrm{X})\end{array}$ & $\begin{array}{c}\text { Shopping Emotion } \\
\text { Pleasure } \\
(\mathrm{Z})\end{array}$ \\
\hline
\end{tabular}

Gambar 3. Persamaan Regresi X dan Z 
3) Meregres $Y=\rho m x X+p m x Z+\varepsilon_{3}$, dan menguji hipotesis bahwa shopping emotion pleasure $(\mathrm{Z})$ berpengaruh terhadap impulse buying $(\mathrm{Y})$.

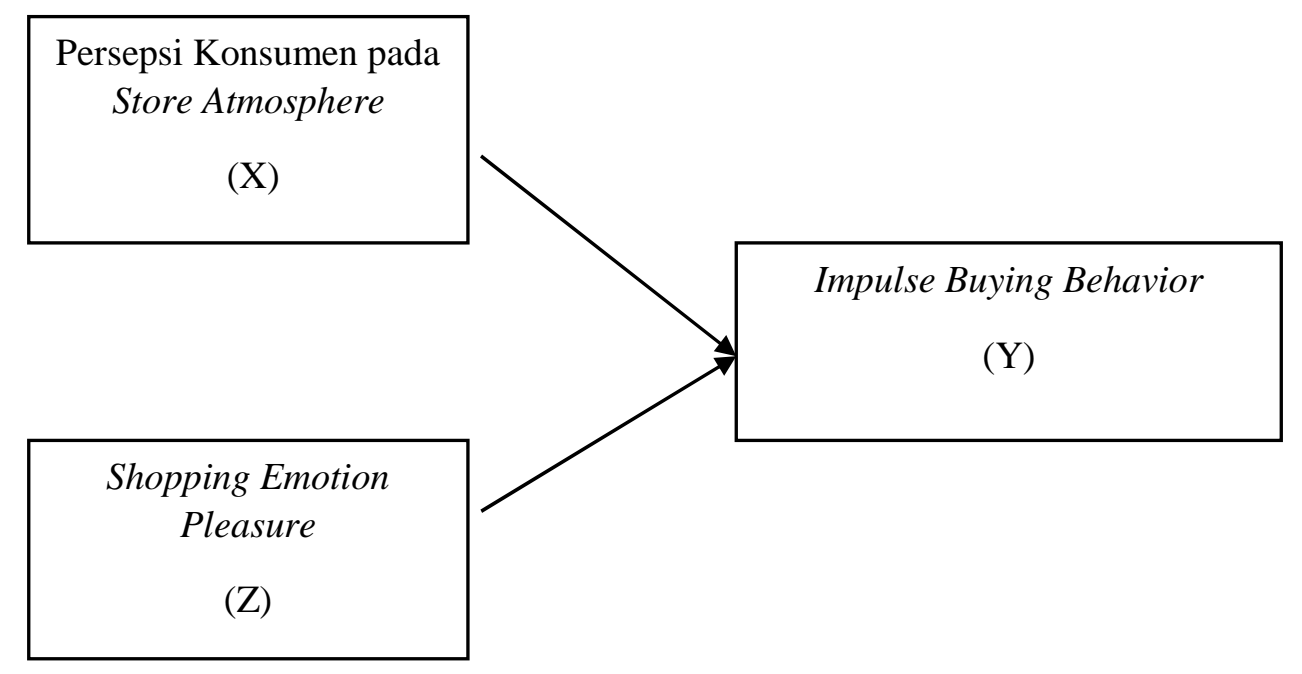

Gambar 4. Persamaan Regresi X dan Z terhadap Y

Variabel shopping emotion pleasure (Z) disebut sebagai mediator (M)/ Intervening jika memenuhi kriteria berikut ini

1. Jika pada persamaan $\mathrm{I}$, variabel indepanden $(\mathrm{X})$ berpengaruh positif terhadap variabel dependen (Y).

2. Jika pada persamaan II, variabel independen (X) berpengaruh positif terhadap variabel yang diduga sebagai variabel mediasi $(\mathrm{M} / \mathrm{Z})$.

3. Jika pada persamaan III, variabel yang diduga sebagai variabel mediasi $(\mathrm{M} / \mathrm{Z})$ berpengaruh terhadap variabel dependen $(\mathrm{Y})$

Selanjutnya Variabel M (Z) dinyatakan sebagai variabel mediasi sempurna (perfect Mediation) jika setelah memasukkan variabel $\mathrm{M}(\mathrm{Z})$, pengaruh variabel $\mathrm{X}$ terhadap $\mathrm{Y}$ yang tadinya signifikan (sebelum memasukkan variabel $\mathrm{M} / \mathrm{Z}$ ) menjadi tidak signifikan. Variabel M (Z) dinyatakan sebagai variabel mediasi parsial (partial mediation) jika setelah memasukkan variabel $\mathrm{M}(\mathrm{Z})$, pengaruh variabel $\mathrm{X}$ terhadap Y yang tadinya signifikan (sebelum memasukkan variabel M) menjadi 
tetap signifikan setelah memasukkan variabel M kedalam model persamaan regresi (Suliyanto; 2011)

\section{HASIL ANALISIS DAN PEMBAHASAN}

\section{Pengujian Instrumen}

Hasil uji validitas instrumen koesioner untuk setiap item pertanyaan/ pernyataan dalam setiap variabel yang dilakukan dengan menggunakan pendekatan Product Moment dari Karl Pearson tersaji pada Tabel 1.

Tabel 1. Hasil Uji Validitas

\begin{tabular}{lcc}
\hline \multicolumn{1}{c}{ Variabel } & R Hitung & Keterangan \\
\hline Store Atmosphere & $0,455-0,723$ & Valid \\
Shopping Emotion Pleasure & $0,836-0,902$ & Valid \\
Impulse buying & $0,758-0,847$ & Valid \\
\hline
\end{tabular}

Sumber: Data Primer diolah 2018

Nilai $r$ tabel yang digunakan dalam penelitian ini adalah 0,1965. Artinya, pernyataan dikatakan valid jika nilai hitung korelasi di atas 0,1965. Tabel 1 menunjukkan bahwa semua pernyataan di setiap variabel yang digunakan valid karena nilai $\mathrm{r}$ hitung berkisar antara 0,455 hingga 0,902 dan itu berarti lebih besar dari nilai $r$ tabel 0,1965 .

Reliabilitas suatu alat ukur dikatakan baik apabila hasil perhitungan koefisien reliabiltas lebih dari 0,60. Hasil uji reliabilitas instrumen penelitian ditunjukkan pada Tabel 2. Hasil uji reliabilitas pada Tabel 2 menunjukkan bahwa nilai Cronbach's Alpha dari keseluruhan pernyataan dalam variabel lebih besar dar 0,60. Hal ini menunjukkan bahwa pernyataan dalam instrumen kuesioner yang digunakan dalam penelitian ini dinyatakan reliabel.

\section{Tabel 2. Hasil Uji Reliabilitas}

\begin{tabular}{lcc}
\hline \multicolumn{1}{c}{ Variabel } & Cronbach's Aplha & Keterangan \\
\hline Store Atmosphere & 0,868 & Reliabel \\
Shopping Emotion Pleasure & 0,821 & Reliabel \\
Impulse buying & 0,739 & Reliabel \\
\hline
\end{tabular}

Sumber: Data Primer diolah 2018 


\section{Deskripsi Responden}

Responden penelitian ini terdiri dari $70 \%$ perempuan, sisanya adalah laki-laki sebagimana tersaji pada Gambar 5.

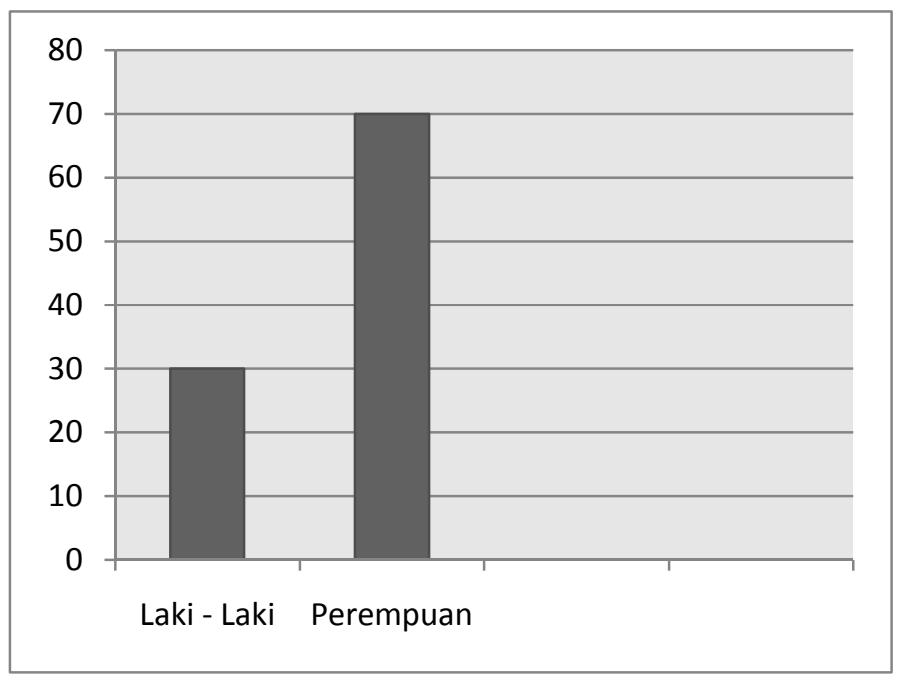

Gambar 5. Karakteristik Responden Berdasarkan Jenis Kelamin Sumber: data primer yang diolah 2018

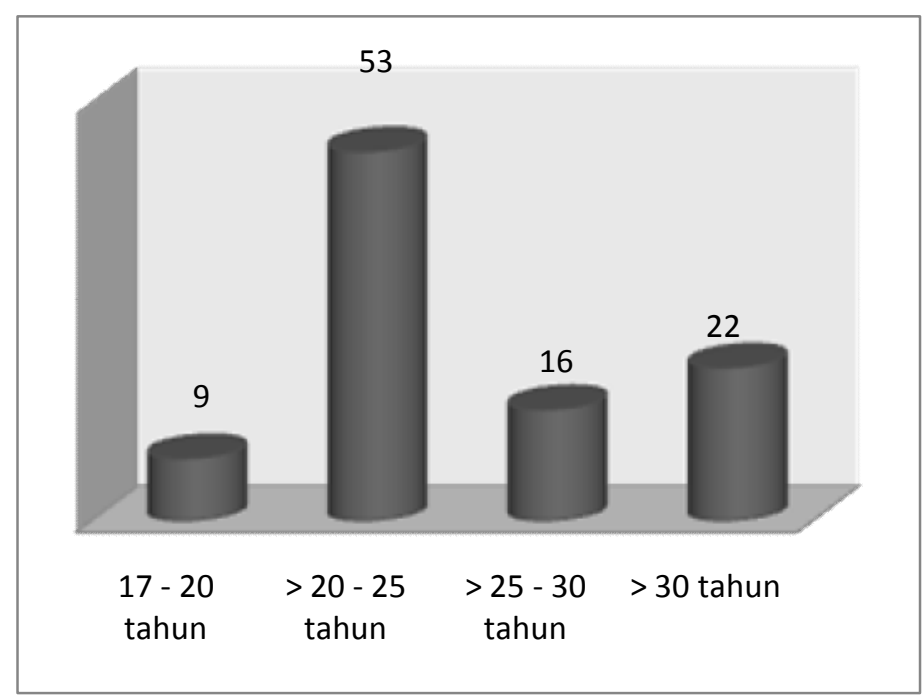

Gambar 6. Karakteristik Responden berdasarkan Usia Sumber: data primer yang diolah 2018 
Bila dilihat dari usia, 53\% usia responden lebih dari 20 sampai dengan 25 tahun. Terbanyak kedua yaitu $22 \%$ berusia lebih dari 30 tahun dan responden yang berusia antara 17 tahun hingga 20 tahun hanya 9\% (lihat Gambar 6)

Berdasarkan pekerjaan, mayoritas responden adalah pelajar/ mahasiswa yaitu $55 \%$ dan terbanyak kedua adalah pegawai swasta yaitu 23\%. Yang berstatus PNS 6\%. Yang status pekerjaannya selain pelajar/ mahasiswa/ pegawai negeri ataupun pegawai swasta sebanyak $16 \%$.

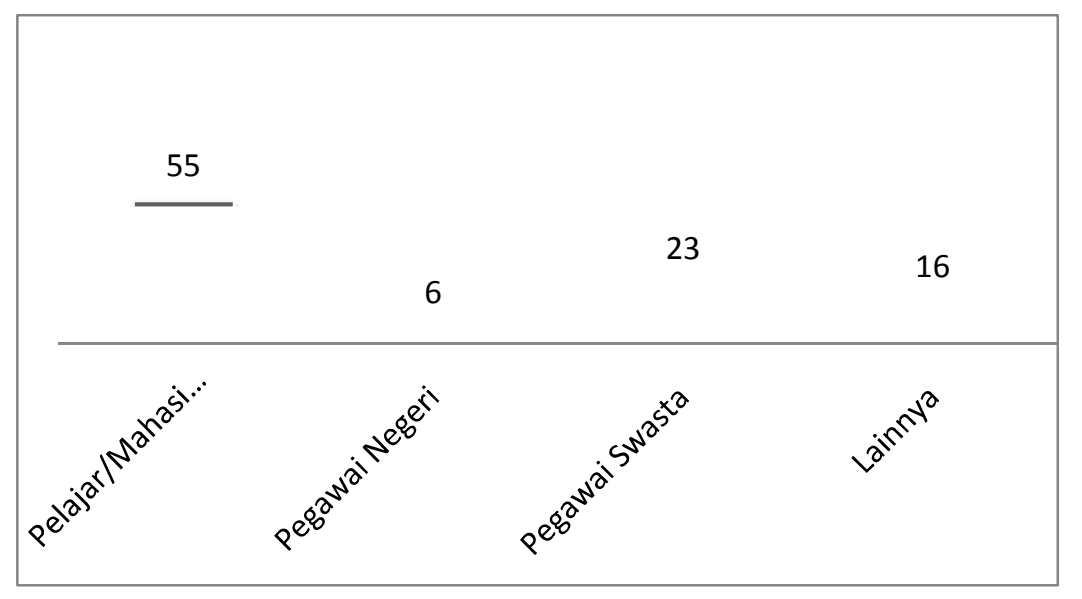

Gambar 7. Karakteristik responden Berdasarkan pekerjaan

Sumber: data primer yang diolah 2018

\section{Deskripsi Variabel}

Analisis deskriptif variabel digunakan untuk mendapatkan gambaran mengenai variabel mean. Dengan interval 0,80 maka rentang skor untuk kepentingan pengkategorian tersaji pada Tabel 3.

Tabel 3. Rentang Skor dan Kategori

\begin{tabular}{cccc}
\hline Rentang & Store Atmosphere & $\begin{array}{c}\text { Shopping Emotion } \\
\text { Pleasure }\end{array}$ & Impulse buying \\
\hline $1,00-1,80$ & Sangat Buruk & Sangat Rendah & Sangat Rendah \\
$1,81-2,61$ & Buruk & Rendah & Rendah \\
$2,62-3,41$ & Netral & Netral & Netral \\
$3,42-4,22$ & Baik & Tinggi & Tinggi \\
$4,23-5,00$ & Sangat Baik & Sangat Tinggi & Sangat Tinggi \\
\hline
\end{tabular}

Sumber: Data Primer, diolah 2018

\section{Persepsi Konsumen pada Store Atmosphere}

Rata-rata jawaban responden terhadap store atmosphere adalah 4,14 (lihat Tabel 4). Berdasarkan rentang skor analisis, 4,14 menunjukkan bahwa pada saat 
dilakukan penelitian, konsumen pada umumnya menilai bahwa store atmosphere di Mirota Kampus Babarsari adalah baik.

Tabel 4. Hasil Analisis Deskriptif Store Atmosphere Toko Swalayan Mirota Kampus Babarsari Yogyakarta

\begin{tabular}{|c|c|c|c|c|}
\hline Dimensi & Mean & Aspek & Mean & Kategori \\
\hline \multirow{4}{*}{ Exteriror } & \multirow{4}{*}{3,99} & Pintu masuk tidak crowded & 3,77 & Baik \\
\hline & & $\begin{array}{l}\text { Kebersihan lingkungan di } \\
\text { luar toko }\end{array}$ & 4,10 & Baik \\
\hline & & Tempat parkir teratur & 4,11 & Baik \\
\hline & & $\begin{array}{l}\text { Pencahayaan di dalam toko } \\
\text { tidak silau }\end{array}$ & 4,30 & Sangat Baik \\
\hline \multirow{6}{*}{$\begin{array}{l}\text { General } \\
\text { Interior }\end{array}$} & \multirow{6}{*}{4,23} & $\begin{array}{l}\text { Musik yang memberikan } \\
\text { suasana rileks }\end{array}$ & 4,23 & Sangat Baik \\
\hline & & Suhu udara sejuk & 4,21 & Baik \\
\hline & & $\begin{array}{l}\text { Karyawan toko tidak } \\
\text { mengganggu }\end{array}$ & 4,34 & Sangat Baik \\
\hline & & Kebersihan di dalam toko & 4,27 & Sangat Baik \\
\hline & & Aroma di dalam toko segar & 4,04 & Baik \\
\hline & & $\begin{array}{l}\text { Kelancaran pergerakan jalur } \\
\text { pengunjung }\end{array}$ & 4,15 & Baik \\
\hline \multirow[t]{2}{*}{$\begin{array}{l}\text { Store } \\
\text { Layout }\end{array}$} & \multirow[t]{2}{*}{4,07} & $\begin{array}{l}\text { Penataan barang di dalam } \\
\text { toko memudahkan } \\
\text { mengambil produk }\end{array}$ & 4,26 & Sangat Baik \\
\hline & & Jarak antar rak tidak sempit & 3,82 & Baik \\
\hline \multirow{3}{*}{$\begin{array}{l}\text { Interior } \\
\text { Point of } \\
\text { Interest } \\
\text { Display } \\
\end{array}$} & \multirow{3}{*}{4,22} & $\begin{array}{l}\text { Warna cat dinding di dalam } \\
\text { toko }\end{array}$ & 4,30 & Sangat Baik \\
\hline & & $\begin{array}{l}\text { Pemasangan tanda petunjuk } \\
\text { jelas }\end{array}$ & 4,14 & Baik \\
\hline & & Mean & 4,14 & Baik \\
\hline
\end{tabular}

Sumber: Data Primer, diolah 2018

\section{Shopping Emotion Pleasure}

Rata-rata skor jawaban responden atas pertanyaan/ pernyataan terkait Shopping Emotion Pleasure yang dirasakan adalah 4,32 (Lihat Tabel 5). Angka tersebut menunjukkan bahwa pada saat penelitian dilakukan, pada umumnya responden merasa shopping emotion pleasure pada saat berbelanja di Mirota Kampus Babarsari sangat positif. 
Tabel 5. Hasil Analisis Deskriptif Shopping Emotion Pleasure

\begin{tabular}{lcc}
\hline \multicolumn{1}{c}{ Indikator } & Mean & Kategori \\
\hline $\begin{array}{l}\text { Perasaan senang saat } \\
\text { berada di dalam toko }\end{array}$ & 4,38 & Sangat positif \\
$\begin{array}{l}\text { Merasa betah berlama- } \\
\text { lama di dalam toko }\end{array}$ & 4,25 & Sangat positif \\
$\begin{array}{l}\text { Perasaan nyaman saat } \\
\text { berada di dalam toko }\end{array}$ & 4,33 & Sangat positif \\
\hline \multicolumn{1}{c}{ Mean } & 4,32 & Sangat positif \\
\hline
\end{tabular}

Sumber: Data Primer, diolah 2018

\section{Impulse buying}

Skor jawaban responden atas pertanyaan/ pernyataan memiliki rata-rata sebesar 4,38. Berdasarkan rentang skor analisis, 4,38 (lihat Tabel 6) menunjukkan bahwa Konsumen yang menjadi responden pada saat di lakukan penelitian memiliki kecenderungan impulse buying yang cenderung sangat tinggi.

Tabel 6. Hasil Analisis Deskriptif Impulse buying

\begin{tabular}{lcc}
\hline \multicolumn{1}{c}{ Indikator } & Mean & Kategori \\
\hline $\begin{array}{l}\text { Membeli produk tanpa } \\
\text { perencanaan }\end{array}$ & 4,43 & Sangat Tinggi \\
$\begin{array}{l}\text { Pembelian produk tidak } \\
\text { memerlukan pertimbangan } \\
\text { panjang }\end{array}$ & 4,21 & Tinggi \\
$\begin{array}{l}\text { Pembelian produk dilakukan } \\
\text { bukan karena kebutuhan }\end{array}$ & 4,51 & Sangat Tinggi \\
\hline Mean & 4,38 & Sangat Tinggi \\
\hline
\end{tabular}

Sumber: Data Primer, diolah 2018

\section{Analisis Jalur}

\section{Uji Prasyarat Analisis}

Uji prasyarat analisis dilakukan untuk mengetahui apakah model regresi yang dibuat dapat digunakan sebagai alat prediksi yang baik. Uji prasyarat analisis yang dilakukan dalam penelitian ini adalah uji normalitas dan uji heterokedastisitas.

\section{Uji Normalitas}

Uji normalitas bertujuan untuk menguji apakah dalam model regresi, variabel pengganggu atau residual memiliki distribusi normal. Pedoman yang digunakan untuk dapat mengetahui residual berdistribusi normal atau tidak dengan melihat pada nilai signifikansi pada hasil uji Kolmogoro- Smirnov. Jika nilai Sig >=0,05 maka 
dapat disimpulkan bahwa data berdistribusi normal. Tabel 3 adalah hasil uji normalitasnya.

Tabel 3. Hasil Uji Normalitas

\begin{tabular}{|c|c|c|}
\hline \multicolumn{2}{|c|}{ One-Sample Kolmogorov-Smirnov Test } & \multirow{2}{*}{$\begin{array}{c}\text { Unstandardized Residual } \\
100\end{array}$} \\
\hline $\mathrm{N}$ & & \\
\hline \multirow[t]{2}{*}{ Normal Parameters ${ }^{\mathrm{a}, \mathrm{b}}$} & Mean & .00 \\
\hline & Std. Deviation & 1.334 \\
\hline Most Extreme & Absolute & .064 \\
\hline \multirow[t]{2}{*}{ Differences } & Positive & .048 \\
\hline & Negative & -.064 \\
\hline \multicolumn{2}{|l|}{ Kolmogorov-Smirnov Z } & .637 \\
\hline \multicolumn{2}{|l|}{ Asymp. Sig. (2-tailed) } & .812 \\
\hline
\end{tabular}

Sumber: Data Primer, diolah 2018.

\section{Uji Heterokedastisitas}

Uji heterokedastisitas bertujuan untuk menguji apakah dalam model regresi terjadi ketidaksamaan varians dari residual satu pengamatan ke pengamatan lainnya. Pada penelitian ini, pengujian untuk melihat adanya gejala heteroskedastisitas dilakukan dengan uji Glejser. Dasar pengambilan keputusan pada uji Glejser adalah jika nilai Sig. $>=0,05$ maka tidak terjadi heteroskedastisitas.

Tabel 4. Hasil Uji Heterokedastisitas

\begin{tabular}{|c|c|c|c|c|c|c|}
\hline & & $\begin{array}{r}\text { Unstand } \\
\text { Coeffi }\end{array}$ & $\begin{array}{l}\text { rdized } \\
\text { ients }\end{array}$ & $\begin{array}{l}\text { Standardized } \\
\text { Coefficients }\end{array}$ & & \\
\hline & Model & B & Std. Error & Beta & $\mathrm{t}$ & Sig. \\
\hline 1 & (Constant) & $-9.437 \mathrm{E}-$ & 1.654 & & .000 & 1.000 \\
\hline & Store Atmosphere & 17 & .033 & .000 & .000 & 1.000 \\
\hline & Shopping & .000 & .107 & .000 & .000 & 1.000 \\
\hline & Emotion & .000 & & & & \\
\hline
\end{tabular}

Sumber: Data Primer, diolah 2018.

Berdasarkan hasil pengujian Tabel 4, nilai signifikansi persepsi konsumen pada store atmosphere sebesar 1,00>0,05 dan nilai signifikansi shopping emotion pleasure sebesar 1,00>0,05. Ini berarti model regresi bebas heterokedastisitas. 


\section{Analisis Jalur}

Analisis jalur dilakukan dengan menggunakan alat bantu SPSS. Hasil analisis hirarchy regression yang dilakukan dengan analisis jalur dengan taraf signifikansi $5 \%$ atau 0,05 tersaji pada Tabel 5 .

Tabel 5. Hasil Analisis Jalur Regresi Hirarkhi

\begin{tabular}{|c|c|c|c|c|c|c|}
\hline \multirow[b]{2}{*}{ Pengaruh } & \multirow[b]{2}{*}{ Variabel } & \multirow[b]{2}{*}{ Sig } & \multirow[b]{2}{*}{$\begin{array}{c}\text { Koefisien } \\
\text { (Beta) }\end{array}$} & \multicolumn{2}{|c|}{ Pengaruh } & \multirow[b]{2}{*}{$\begin{array}{l}\text { Pengaruh } \\
\text { Total }\end{array}$} \\
\hline & & & & Langsung & $\begin{array}{c}\text { Tidak } \\
\text { Langsung }\end{array}$ & \\
\hline $\begin{array}{c}\mathrm{X} \\
\text { terhadap } \\
\mathrm{Y}\end{array}$ & $X$ & 0,001 & 0,388 & 0,388 & $\begin{array}{c}0,202 \\
(0,537 \mathrm{X} \\
0,378)\end{array}$ & 0,540 \\
\hline $\begin{array}{c}\mathrm{X} \\
\text { terhadap } \\
\mathrm{Z}\end{array}$ & $X$ & 0,000 & 0,537 & 0,537 & (3) & 0,537 \\
\hline $\begin{array}{l}\mathrm{X} \text { dan } \mathrm{Z} \\
\text { terhadap }\end{array}$ & $X$ & 0,208 & 0,132 & $\begin{array}{l}\text { Tidak ada } \\
\text { pengaruh }\end{array}$ & $\begin{array}{l}\text { Tidak ada } \\
\text { pengaruh }\end{array}$ & - \\
\hline $\mathrm{Y}$ & $\mathrm{Z}$ & 0,001 & 0,378 & 0,378 & - & 0,378 \\
\hline & $z_{1}$ & & 0,886 & 0,886 & - & 0,886 \\
\hline & & & 0,712 & 0,712 & - & 0,712 \\
\hline & $\Sigma_{2}$ & & & & & \\
\hline & $\varepsilon_{3}$ & & 0,784 & 0,784 & - & 0,763 \\
\hline
\end{tabular}

Sumber: Data Primer, diolah 2018.

Hasil analisis jalur yang tersaji pada Tabel 5 menunjukkan nilai Sig untuk hipotesis 1 yang menyatakan bahwa persepsi konsumen pada store atmosphere (X) berpengaruh terhadap impulse buying (Y) adalah sebesar 0,001 dan nilai tersebut < 0,05. Dengan demikian terdapat cukup bukti secara statistik bahwa hipotesis 1 yang menyatakan bahwa persepsi konsumen pada store atmosphere berpengaruh terhadap impulse buying dapat diterima. Temuan menunjukkan bahwa persepsi konsumen pada store atmosphere yang baik akan meningkatkan kecenderungan konsumen untuk melakukan pembelian yang tidak direncanakan. Temuan ini mendukung pendapat dari Kotler dan Keller (2009:166) yang mengemukakan bahwa perilaku pembelian konsumen dipengaruhi oleh beberapa faktor budaya, sosial, pribadi, dan psikologi. Menurut Kotler dan Keller (2009) dalam memahami perilaku konsumen, 
beberapa faktor psikologis yang berpengaruh terhadap pembelian diantaranya motivasi, persepsi, pembelajaran, dan memori. Selain itu, hasil temuan penelitian ini juga mendukung hasil penelitian dari Supriono (2017) yang meneliti tentang pengaruh store atmosphere terhadap shopping emotion dan impulse buying (studi pada Supermarket Giant, Dinoyo, Malang). Hasil dari penelitian tersebut adalah store atmosphere berpengaruh terhadap impulse buying.

Hasil analisis jalur yang tersaji pada Tabel 5 juga menunjukkan bahwa nilai Sig untuk hipotesis 2 yang menyatakan persepsi konsumen pada store atmosphere (X) berpengaruh terhadap shopping emotion pleasure (Z) adalah sebesar 0,000 dan nilai tersebut lebih kecil daripada 0,05. Dengan demikian dapat dikatakan bahwa secara statistik terdapat cukup bukti untuk menerima hipotesis 2 tersebut. Artinya, terdapat cukup bukti secara statistik bahwa persepsi konsumen pada store atmosphere berpengaruh terhadap shopping emotion pleasure. Oleh karena nilai koefisien bertanda positif, maka makin baik persepsi pada store atmosphere akan menimbulkan shopping emotion pleasure atau emosi yang makin positif pada diri konsumen. Temuan yang demikian itu mendukung pendapat Sangadji dan Sopiah (2013:64) yang menyatakan bahwa persepsi konsumen merupakan suatu proses yang timbul akibat adanya sensasi. Sensasi adalah aktivitas merasakan atau penyebab keadaan emosi. Selain itu, temuan ini juga menguatkan temuan penelitian Anggoro (2013) bahwa store atmosphere yang dirasakan konsumen mempengaruhi emotional responses konsumen tersebut.

Hasil analisis regresi berganda persamaan $Y=p m x X+p m x Z+\varepsilon_{3}$ dan pengujian hipotesis 3 yang menyatakan shopping emotion pleasure $(\mathrm{Z})$ berpengaruh terhadap impulse buying (Y) menunjukkan nilai Sig. sebesar 0,001 yang lebih kecil dari nilai 0,05. Dengan demikian, secara statistik terdapat cukup bukti untuk menerima hipotesis yang menyatakan shopping emotion pleasure berpengaruh terhadap impulse buying dengan nilai koefisien bertanda positif. Shopping emotion pleasure atau emosi positif yang terbentuk pada diri konsumen akan meningkatkan kecenderungan impulse buying konsumen saat berbelanja. Hal demikian mendukung pendapat dari Hawkins dan Mothersbaugh (2016:370) yang menyatakan bahwa emosi yang sangat terkait dengan kebutuhan, motivasi, juga kepribadian merupakan suatu perasaan yang kuat dan relatif tidak dapat dikendalikan namun dapat 
memengaruhi perilaku atau kebiasaan seseorang. Selain itu, Solomon (2007) menyatakan bahwa suasana hati atau emosi seseorang atau kondisi psikologi seseorang saat pembelian dapat memiliki dampak besar pada apa yang dia beli atau bagaimana dia menilai pembeliannya.

Lebih jauh hasil analisis jalur dengan regresi hirarkhi pada Tabel 5 menunjukkan bahwa ketika shopping emotion pleasure ditambahkan sebagai variabel independen bersama-sama dengan persepsi konsumen pada store atmosphere, nilai Sig variabel persepsi konsumen pada store atmosphere sebesar 0,208 yang lebih besar dari 0,05. Artinya bahwa ketika shopping emotion pleasure ditambahkan sebagai variabel independen bersama-sama dengan persepsi konsumen pada store atmosphere, yang terjadi adalah persepsi konsumen pada store atmosphere tidak berpengaruh terhadap impulse buying.

Oleh karena persepsi konsumen pada store atmosphere berpengaruh terhadap shopping emotion pleasure dan impulse buying, sementara persepsi konsumen pada store atmosphere terhadap impulse buying menjadi tidak berpengaruh setelah memasukkan variabel shopping emotion pleasure maka dapat dikatakan bahwa variabel shopping emotion pleasure merupakan variabel intervening yang memediasi secara sempurna (perfect mediation). Dengan demikian penelitian ini menemukan bahwa persepsi konsumen pada store atmosphere berpengaruh terhadap impulse buying yang dimediasi penuh atau sempurna oleh shopping emotion pleasure. Temuan ini mendukung temuan penelitian sebelumnya yang dilakukan oleh Saad dan Madiha (2015) yang menyatakan bahwa shop enjoyment dalam hal ini shopping emotion pleasure memediasi secara sempurna pengaruh antara persepsi konsumen pada store environment factors dan impulse buying

\section{KESIMPULAN}

Penelitian ini memberikan kesimpulan bahwa, pertama, persepsi konsumen pada store atmosphere berpengaruh terhadap impulse buying. Kedua, persepsi konsumen pada store atmosphere berpengaruh terhadap shopping emotion pleasure. Yang ketiga adalah shopping emotion pleasure berpengaruh terhadap impulse buying. Penelitian ini juga menemukan bahwa pengaruh persepsi konsumen pada 
store atmosphere terhadap impulse buying dimediasi secara sempurna atau penuh oleh shopping emotion pleasure.

Oleh karena persepsi konsumen pada store atmosphere berpengaruh terhadap impulse buying melalui shopping emotion pleasure, maka hal tersebut memberikan implikasi praktis terhadap upaya manajer toko khususnya toko swalayan Mirota Kampus Babarsari Yogyakarta dalam mendorong terjadinya pembelian yang lebih banyak. Inovasi store atmosphere terutama pada dimensi eksterior yang memiliki skor rata-rata terendah seperti misalnya memperluas pintu masuk Mirota Kampus Babarsari Yogyakarta agar konsumen dapat lebih leluasa untuk masuk dan keluar dari toko, meningkatkan kebersihan di lingkungan luar toko dan meningkatkan fasilitas parkir yang ada di Mirota Kampus Babarsari adalah perlu.

Mengingat bahwa persepsi konsumen pada store atmosphere berpengaruh terhadap impulse buying yang dimediasi secara sempurna oleh shopping emotion pleasure, maka menjadi perlu untuk setidaknya melakukan penelitian serupa dengan memperluas cakupan subyek penelitian mengingat penelitian ini cakupan subyek terbatas pada kasus tertentu, sehingga memiliki keterbatasan dalam generalisasi. Lain dari itu variabel dalam penelitian ini masih sangat mungkin untuk dikembangkan baik untuk hal-hal yang mempengaruhi shopping emotion pleasure maupun impulse buying. Selebihnya perlu dilakukan pengujian prasyarat secara lebih lengkap.

\section{DAFTAR REFERENSI}

Akram, U., Hui, P., Khan, M. K., Hashim, M., \& Rasheed, S., 2016, Impact of Store Atmosphere on Impulse Buying Behaviour: Moderating Effect of Demographic Variables. International Journal of $U$ - and E- Service, Science and Technology, 9(7), 43-60. doi:10.14257/ijunesst.2016.9.7.05

Anggoro, Puspasari Sandra. 2013. Analisis Pengaruh Store Atmosphere Terhadap Impulse Buying Behavior Melalui Emotional Response Di Matahari Departement Store Tunjungan Plaza Surabaya. Tidak dipublikasikan.

Daniel Goleman, Daniel, 1996, Emotional Intelligence, New ed, Sydney Bloomsbury Publishing PLC 
Habib, M. D., \& Qayyum, A., 2018,. Cognitive Emotion Theory and Emotion-Action Tendency in Online Impulsive Buying Behavior. Journal of Management Sciences, 5(1), 86-99. doi:10.20547/jms.2014.1805105

Hawkins, D. I and David L Mothersbaugh, 2016, Consumer behavior: Building Marketing Strategy. Thirteenth edition New York, NY: McGraw-Hill Education.

Hawkins, D. I and David L Mothersbaugh, 2010. Consumer Behavior: Building Maketing Strategy. $11^{\text {th }}$ edition. Mc-Graw-Hill, Irwin.

Ichsanti. Pengertian Variabel Independen, Dependen, Moderating, Serta Intervenig. https://www.akuntansilengkap.com. Diakses tanggal 5 September 2018.

Kotler, P., \& Keller, K. L. ,2016, Marketing management global edition. Boston: Pearson.

Kotler, Philip. Armstrong, Gary. 2008. Dasar-dasar pemasaran: Principles of Marketing. Jakarta: Prenhallindo.

Lee, G. Y., \& Yi, Y. , 2008,. The Effect of Shopping Emotions and Perceived Risk on Impulsive Buying: The Moderating Role of Buying Impulsiveness Trait. Seoul Journal of Business, 14(2), 1.

Levy, M., \& Weitz, B. A., 2012. Retailing management (Eighth ed.). New York: McGraw-Hill/Irwin.

Mattila, A. S., \& Wirtz, J. 2008. The role of store environmental stimulation and social factors on impulse purchasing. Journal of Services Marketing, 22(7), 562-567. doi:10.1108/08876040810909686

Mowen, C. John. Minor, Michael. 2002. Perilaku Konsumen. Jakarta: Erlangga.

Saad,Mohamad and Madiha Metawie, 2015, Store Environment, Personality Factors and Impulse Buying Behavior in Egypt: The Mediating Roles of Shop Enjoyment and Impulse Buying Tendencies, Journal of Business and Management Sciences, 2015, Vol. 3, No. 2, 69-77

Sangadji. Sopiah. 2013. Perilaku Konsumen: Pendekatan Praktis Disertai Himpunan Jurnal Penelitian. Yogyakarta: Andi Ofset.

Schiffman, L. G., \& Wisenblit, J., 2015. Consumer Behavior (Eleventh ed.). Harlow: Pearson Education. 
Shen, C. H., \& Tsuifang, H., 2011. The effect of atmosphere on customer perceptions and customer behavior responses in chain store supermarkets. African Journal of Business Management, 5(24), 10054-10066. doi:10.5897/ajbm10.608

Solomon, M., Bamossy, G., \& Askegaard, S. (2007). Consumer behavior a European perspective. Harlow: Financial Times/Prentice Hall.

Solomon, Michael. Rabolt, Nancy. 2014. Consumer Behavior: In Fashion. $2^{\text {nd }}$ Boston: Pearson.

Sugiyono. 2016. Metode Penelitian Bisnis. Bandung: Alfabeta.

Sugiyono. 2010. Metode Penelitian Kuantitatif, Kualitatif, dan $R \& D$. Bandung: Alfabeta.

Suliyanto. 2011. Ekonometrika Terapan Teori dan Aplikasi dengan SPSS.Yogyakarta: CV. Andi Offiset.

Supriono, Pratomo Bramantyo. 2017. Pengaruh Store Atmosphere Terhadap Shopping Emotion dan Impulse Buying. Jurnal Administrasi Bisnis. Vol.50.

Wikipedia. Atmospheric. [Online]. https://en.m.wikipedia.org/wiki/Atmosperic. Diakses tanggal 7 September 2018.

Wikipedia. Atmosphere. [Online]. https://en.m.wikipedia.org/wiki/Atmosphere. Diakses tanggal 7 September 2018.

Zulganef. 2008. Metode Penelitian Sosial \& Bisnis. Edisi Pertama. Yogyakarta: Graha Ilmu.

http://administrasibisnis.studentjournal.ub.ac.id/index.php/jab/article/view/1962.

Diakses tanggal 10 September 2018.

https://dosen.perbanas.id/variabel-moderator-dan-mediator/.Diakses 5-8--2018. https://www.mirotakampus.com/id. Diakses tanggal 1 November 2018. 